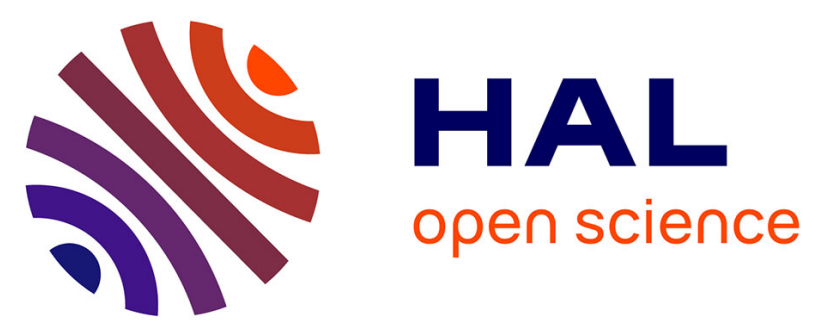

\title{
Effect of thermal aging on crystallization behaviors and dynamic mechanical properties of glass fiber reinforced polyphenylene sulfide (PPS/GF) composites
}

Peiyuan Zuo, Abbas Tcharkhtchi, Mohammadali Shirinbayan, Joseph Fitoussi, Farid Bakir

\section{To cite this version:}

Peiyuan Zuo, Abbas Tcharkhtchi, Mohammadali Shirinbayan, Joseph Fitoussi, Farid Bakir. Effect of thermal aging on crystallization behaviors and dynamic mechanical properties of glass fiber reinforced polyphenylene sulfide (PPS/GF) composites. Journal of Polymer Research, 2020, 27, pp.77. 10.1007/s10965-020-02051-2 . hal-02538232

\section{HAL Id: hal-02538232 \\ https://hal.science/hal-02538232}

Submitted on 9 Apr 2020

HAL is a multi-disciplinary open access archive for the deposit and dissemination of scientific research documents, whether they are published or not. The documents may come from teaching and research institutions in France or abroad, or from public or private research centers.
L'archive ouverte pluridisciplinaire HAL, est destinée au dépôt et à la diffusion de documents scientifiques de niveau recherche, publiés ou non, émanant des établissements d'enseignement et de recherche français ou étrangers, des laboratoires publics ou privés. 


\title{
Effect of thermal aging on crystallization behaviors and dynamic mechanical properties of glass fiber reinforced polyphenylene sulfide (PPS/GF) composites
}

\author{
Peiyuan Zuo ${ }^{1}(\mathbb{D}) \cdot$ Abbas Tcharkhtchi $^{1} \cdot$ Mohammadali Shirinbayan $^{1} \cdot$ Joseph Fitoussi $^{1} \cdot$ Farid Bakir $^{2}$
}

\begin{abstract}
In this study, the main purpose is to systematically evaluate isothermal and non-isothermal crystallization behavior of short glass fiber-reinforced polyphenylene sulfide polymer composites (PPS/GF) by a wide range of commonly applied models and also to preciously discuss the crystallization evolution and dynamic mechanical properties together with the consideration of thermal aging effects. Some interesting progress concerning this study can be concluded as follows: the Avrami model was used to examine the isothermal crystallization behavior of PPS/GF and the Avrami plot results exhibit that the isothermal crystallization contains primary and second crystallization process. In terms of non-isothermal crystallization, the Jeriorny model and Mo model could describe the mechanism of nucleation and crystal growth of PPS/GF material under study. Also, the activation energy of non-isothermal crystallization is calculated $(-58.78 \mathrm{~kJ} / \mathrm{mol})$ by Kissinger method. Another important aspect is that thermal aging has an obvious effect on crystallization behaviors of PPS under study. The degree of crystallinity increases from $44 \%$ (virgin sample) to $56 \%$ after $96 \mathrm{~h}$ of aging at $200{ }^{\circ} \mathrm{C}$. After a long period of oxidation up to $1080 \mathrm{~h}$ at $200{ }^{\circ} \mathrm{C}$, the crystallinity degree decreases to $36.6 \%$ due to thermo-oxidation effect. DMA results imply that thermal aging may lead to more crosslinking reactions and result into more restriction of molecule mobility in PPS composite materials.
\end{abstract}

Keywords Poly-Phenylene sulfide (PPS) $\cdot$ Crystallization $\cdot$ Kinetic model $\cdot$ Thermal aging effect $\cdot$ Dynamic mechanical properties

\section{Introduction}

Polyphenylene sulfide (PPS) exhibits good dimensional stability, thermal stability and electrical properties as well as

Peiyuan Zuo

2015-1027@ensam.eu

Abbas Tcharkhtchi

abbas.tcharkhtchi@ensam.eu

Mohammadali Shirinbayan

mohammadali.shirinbayan@ensam.eu

Joseph Fitoussi

joseph.fitoussi@ensam.eu

Farid Bakir

farid.bakir@ensam.eu

1 Arts et Metiers Institute of Technology, CNAM, PIMM, HESAM University, F-75013 Paris, France

2 Arts et Metiers Institute of Technology, CNAM, LIFSE, HESAM University, F-75013 Paris, France mechanical strength. Also, PPS-based materials, when reinforced with glass/carbon fibers/related filaments, have been popularly used as a high-performance material in recent years, not only in terms of structural materials fileds (e.g., aerospace and automibile industries), but also in other various fields such as electrodes, seperators, etc. In last couple of years, there are many literatures focusing these aspects.

On the one hand, some researchers pay much attention to mechanical properties of PPS materials. For example, Park et al. [1] modified PPS composites reinforced with carbon fibers and they found the method of electrophoretic surface deposition of multi-walled carbon nanotubes can improve the flexural properties of PPS composites. Zhao et al. [2] prepared PPS nonwovens with ultra-high content of glass fiber fabrics by thermo-compression lamination method and these nonwovens showed a significant increase in various mechanical properties. Moreover, Backe et al. [3] characterized the ultrasonic fatigue behaviors of carbon fiber fabric reinforced PPS composites for aircraft applications and the authors found that lifetime-oriented investigations at stress ratios between $\mathrm{R}=$ 0.1 and 0.51 exhibited an exponential decrease of the bearable 
stress amplitudes in the range between $10^{\wedge}$ and $10^{\wedge^{9}}$ cycles. Similarly, Stoeffler et al. [4] studied PPS composites reinforced with recycled carbon fiber for aerospace applications and the main findings showed that the recycled carbon fiber reinforced PPS composites had a comparable mechanical properties to equivalent compounds fabricated by industrial grades of short virgin carbon fiber. Also, Maaroufi et al. [5] investigated the post-fire compressive behavior of carbon fibers woven-ply PPS laminates for aeronautical applications and the prior fireexposure led to increased damages due to PPS matrix thermal decomposition. Liu et al. [6] used thermoplastic prepregs in a double-belt press to fabricate carbon fiber reinforced PPS composite and the results showed that a relative lower process velocity $\left(0.2 \mathrm{~m} \cdot \mathrm{min}^{-1}\right)$ could produce this composite with a good tensile and interlaminar shear properties which are comparable to that of compression-molded composites.

On the other hand, PPS-based materials also have other important applications in various fields. For example, Aramid nanofiber / PPS nonwoven composite separator was fabricated by Zhu et al. [7] through a facile papermaking method for lithium ion battery applications and the results showed that the introduced polar aramid nanofibers in the PPS composite separator could dramatically regulate the porosity and improve the following electrode properties. Luo et al. [8] investigated a PPS nonwoven-based composite separator and the authors concluded that PPS nonwoven-based composite possessed higher porosity and air permeability as well as other improved electrical properties when compared with commercialized polyolefin separator. Chitosan modified PPS-based microfiber membrane for effective antibacterial activity and oil-in-water emulsion separation was fabricated by Huang et al. [9] and this membrane had a promising long-term separation in terms of oily wastewater treatment.

To make better use of this material, there are also some fundamental references regarding crystallization behaviors of PPS materials [10-13]. For example, Furushima et al. [14] studied crystallization/melting kinetics of PPS and they found that the half-time crystallization of isothermally meltcrystallized PPS showed a downward convex curve with a minimum at $160^{\circ} \mathrm{C}$. Liu et al. [15] studied the crystal structure of PPS / carbon fiber composites fabricated by additive manufacturing and they found that the intensities of the diffraction peaks originated from PPS increased until the annealing time reached $9 \mathrm{~h}$, which showed an improvement in crystal perfection due to molecular chain rearrangement. Also, nucleating agent plays an important role during crystallization of PPS materials. For example, Deng et al. [16] reported nanodiamond as an efficient nucleating agent for PPS and they clarified that the Avrami equation and Mo method provided that a fairly satisfactory description for the non-isothermal crystallization of PPS in both pure and composite forms. Nanodiamond particles provided a heterogeneous nucleation effect on PPS by remarkably increasing the crystallization temperature and improving the crystallization rate. Moreover, some fillers or particles can also have the effects as nucleating agent. In this aspect, Chen et al. [17] investigated isothermal crystallization kinetics of PPS doped with amorphous carbon or crystalline graphite particles. Both types of carbon forms had been found to affect the crystallization behavior of PPS in some extent. Similarly, Jiang et al. [18] prepared a series of composites by blending PPS with multi-walled carbon nanotubes at 1,2 and $3 \mathrm{wt} \%$ to investigate nucleation effect of hydroxyl-purified multi-walled carbon nanotubes in PPS composites. They revealed that the enthalpy $\Delta \mathrm{H}_{\mathrm{c}}$ of the composites increased with increasing multi-walled carbon nanotubes whereas the crystallization temperature decreased progressively.

Moreover, many researchers take the effect of annealing or curing processes into consideration and these annealing or curing processes could directly affect the crystallization behavior and further other properties such as morphologies and mechanical properties. Lee et al. [19] investigated the effect of curing on the crystallization rates of PPS and PPS/carbon fiber composites by DSC technique. They found the crystallization rate of PPS was enhanced with increasing degree of curing. Moreover, Lu et al. [20] studied the effects of annealing on relaxation behavior of PPS film material. DSC results suggested that annealing caused the PPS film to relax some of its rigid amorphous fraction and increase its crystallinity. DMA results showed a corresponding increase in the temperature location of the dissipation peak and a decrease in its amplitude when $\mathrm{T}_{\alpha}$ increased above $100{ }^{\circ} \mathrm{C}$. Similarly, Lee et al. [21] investigated commercial PPS by thermal curing and they found an increase of molecular weight due to crosslinking. They concluded the crosslinking of PPS affected crystallization behaviors significantly. To a certain extent, crosslinking acted as nucleation agents, but excessive crosslinking hindered the crystallization. Morphology observed by polarized optical microscopy suggested that thermal curing for as little as 1 day contributed to the spherulite structure having a smaller size and that was not observed with pure PPS. Boey et al. [22] analyzed the effect of annealing on the non-linear creep deformation of the PPS composite specimens and indicated that the creep deformation for both 20 and $40 \%$ reinforced samples were relatively similar despite the difference in the amount of fiber reinforcement. In contrast, with the crystallinity percent increasing, the value of the creep stress and strain rate components decreased exponentially. In addition, thermal history should also be taken into consideration as an important factor during crystallization. For example, Chung et al. [23] studied the effect of thermal history on crystal structure of PPS. They found the dimensions of the crystal lattice were depended upon prior thermal conditions. Moreover, Caminiti et al. [24] investigated the PPS isothermal cold crystallization behavior and they showed that the quenching procedure did not secure the perfect reproducibility, which may influence the concentration of these nuclei and the crystallization rate of polymeric materials. 
Also, to meet the increasing requirement for different properties of PPS, PPS was studied in form of blended polymers or reinforced composites. In aspect of blended polymers containing PPS. For example, the effect of Poly ether ether ketone on crystallization and multiple melting behavior of PPS was studied by Mai et al. [25] and they found that an increase in the $T_{c}$ and also the intensity of the $T_{c}$ peak of PPS. Some research also [26] reported pure, glass, carbon and aramid fiber reinforced PPS. They showed the system of aramid fiber/PPS had a much shorter half-time of crystallization than the other three systems. More researches concerning crystallization were focused on various PPS composites. Desio et al. [27] studied the isothermal crystallization from the melt of unreinforced PPS and of carbon, aramid, and glass fiber reinforced PPS composites. The results indicated that the influence of fibers on PPS crystallization was not only fiber specific, but also strongly dependent on the surface treatment. In general, fiber reinforced systems crystallized faster than unreinforced PPS, and the degree of crystallinity was relatively lower. And also, they observed that the rate of crystallization was improved in those systems which exhibited trans-crystallinity in thin PPS film/ single fiber composites. Cole et al. [28] studied the crystallinity in PPS-carbon composites by using diffusion reflection FTIR spectroscopy and DSC techniques, and they found isothermal annealing induced a secondary type of crystallization which gave a structure whose "melting point" was about $15^{\circ} \mathrm{C}$ higher than the annealing temperature. Heating PPS in air at temperature near its melting point caused structural changes, resulting in a lower ultimate degree of crystallinity and a lower melting point.

On the other hand, DMA tool is powerful to study polymer/ polymer miscibility in polymer blends and also measure the glass transition temperature of polymer. Moreover, it can obtain an idea about the storage modulus, loss modulus and damping behavior. Yang et al. [29] prepared PPS/multiwall carbon nanotube composites and observed increased Tg and storage modulus of PPS via DMA. Wu et al. [30] studied thermal behaviors and viscoelastic properties of PPS/epoxy resin by DMA test and showed that the epoxy resin can promote degradation and branching of PPS during melting mixing due to its poor thermal stability.

Reviewing these literatures helps us to get an overall understanding of the crystallization behaviors and dynamic mechanical properties of raw PPS materials. However, there is not so much research concerning the detailed discussion related to the thermal aging effect on crystallization behaviors and dynamic mechanical properties for thermal aged PPS materials. So, it seems very meaningful and important to verify the common models and methodologies for isothermal or nonisothermal crystallization behaviors in PPS composite system under our study, which is reinforced with short glass fibers. Also, it should be emphasized that it is very innovative and significant to consider long-time thermal aging effect on crystallization behaviors and dynamic mechanical properties since this work will make some positive contribution to the further application of PPS materials in practice.

\section{Materials and test techniques}

\section{Materials and sampling}

PPS composite materials are supplied by Valeo Company in France. The details about these materials can be summarized as follows: The supplied PPS is black plate with density of around $1.58 \mathrm{~g} / \mathrm{cm}^{3}$ and the weight percent of glass fiber is $30 \%$. The material has a water absorption of $0.02 \%$. Films with a thickness of $20 \mu \mathrm{m}$ or rectangular plate samples were placed in the ovens (with circulation of air) and the temperatures of aging were chosen from $100^{\circ} \mathrm{C}$ to $200^{\circ} \mathrm{C}$ for different aging time. More details concerning thermal aging process can be seen in our previous publications [31-33].

\section{Characterization methods}

\section{Differential scanning calorimetry (DSC)}

The differential scanning calorimetry (DSC) measurements were carried out with the DSC Q10 V9.0 Build 275 (TA Instruments, Guyancourt, France). The samples of mass between 5 and $10 \mathrm{mg}$ were placed in hermetic aluminum capsules. The sample was heated up to $300^{\circ} \mathrm{C}$ with a temperature rate of $10{ }^{\circ} \mathrm{C} / \mathrm{min}$ under the atmosphere of Nitrogen $(40 \mathrm{ml} /$ min) and was kept at this temperature for $10 \mathrm{~min}$. Subsequently, it was cooled down with different cooling rates $\left(5 \sim 25{ }^{\circ} \mathrm{C} / \mathrm{min}\right)$ to observe the non-isothermal crystallization behaviors or it was cooled down to some fixed temperatures to see the isothermal crystallization behaviors.

The degree of crystallinity $X_{C}$ is calculated from the following relationship:

$X_{C}=\frac{\Delta H_{f}}{\Delta \mathrm{H}_{f}^{0} * \varphi} * 100 \%$

With $X_{C}=$ crystallinity degree, $\Delta H_{f}=$ enthalpy of fusion, $\Delta \mathrm{H}_{f}^{0}=$ pure crystalline phase enthalpy of fusion, $\varphi=$ percent of matrix.

\section{Dynamic mechanical analysis}

Dynamic Mechanical Analysis (DMA) tests were carried out using the Q800 DMA instrument to measure major transition temperatures and viscoelastic behavior. These tests were conducted under the following conditions: the first step is to do an alternating bending configuration in our case and then the selected test temperatures were chosen between $25{ }^{\circ} \mathrm{C}$ and 
$200{ }^{\circ} \mathrm{C}$. The frequency is chosen at 1 or $10 \mathrm{~Hz}$ with the increasing temperature rate of $0.5{ }^{\circ} \mathrm{C} / \mathrm{min}$. The sample had a rectangular shape $\left(35 \times 12 \times 3 \mathrm{~mm}^{3}\right)$.

\section{Wide X-ray diffraction}

The Wide X-ray diffraction (WXRD) patterns are scanned by using $\mathrm{Cu}-\mathrm{K} \alpha$ radiation sources operated at $40 \mathrm{KV}$ and $20 \mathrm{~mA}$ with diffraction angle ranging from $3{ }^{\circ}$ to $40^{\circ}$ with the speed of $5 \% \mathrm{~min}$. The diffraction peak is at $2 \theta=20.4^{\circ}$.

\section{Crystallization behaviors of PPS/GF composites}

\section{Isothermal crystallization behavior}

Isothermal thermograms of PPS/GF composites obtained by cooling a molten sample to the isothermal crystallization temperature $\left(T_{c}\right)$ are shown in Fig. 1. It can be seen that the crystallization of PPS/GF is strongly affected by the given $T_{c}$. With increasing the $\mathrm{T}_{\mathrm{c}}$, the peaks tend to be more and more flat and this is mainly due to the decreasing of crystallization rate.

For a general crystallization behavior of polymers, the crystallization weight fraction, $\chi(\mathrm{t})$, is obtained from DSC exotherms of polymers by means of the ratio between the partial area at time $t$ and the total exotherms area, i.e.,

$\chi(t)=\int_{t_{0}}^{t}\left(\frac{d H}{d t}\right) d t / \int_{t_{0}}^{\infty}\left(\frac{d H}{d t}\right) d t$

Where: $\frac{d H}{d t}$ is the heat flow rate and $t_{0}$ is the induction time.

With this following result in Fig. 2, one can conclude that the higher isothermal temperature corresponds to longer relative crystallization time. For example, lower isothermal temperatures below $256{ }^{\circ} \mathrm{C}$ accomplish their crystallization in 5 min while this value for $260^{\circ} \mathrm{C}$ is relatively 3 times higher (with $15 \mathrm{~min}$ ).

Analysis of the crystallization kinetic of PPS composites under isothermal condition is accomplished with the application of the Avrami equation according to the results of DSC. Actually, for a general crystallization kinetics of a semicrystalline polymer, most researchers use developed models based on an Avrami classical theory [34]. In detail, the Avrami treatment concerning crystallinity $\chi$ versus time can be drawn as the following expression:

$1-\chi(t)=\exp \left[-K t^{n}\right]$

Where $\chi(t)$ is the relative crystallinity at time $\mathrm{t}$; $K$, the crystallization rate constant depending on nucleation and growth rates; and n, the Avrami crystallization exponent depending on the nature of nucleation and growth geometry of crystals. Avrami plots can be constructed by plotting $\log [-\ln (1-\chi(t)]$ versus $\log (\mathrm{t})$.

According to the relative crystallinity result above, it is possible to apply Avrami plot to explain the crystallization behavior of PPS/GF under study (see Fig. 3 and Table 1). First of all, with increasing $T_{c}$, the curves tend to shift to higher crystallization time. Moreover, one can see all curves can be divided as three domains including primary crystallization areas as well as two stages and secondary crystallization area. In detail, the curves in two stages of primary crystallization areas tend to be linear while the curves in secondary crystallization areas seem non-linear. Also, the stage 1 in primary area has a very small $\mathrm{k}_{\mathrm{c}}$ (less 0.247 ) and this $\mathrm{k}_{\mathrm{c}}$ corresponds to the rate of crystallization. With increasing $T_{c}$, the $k_{c}$ tends to be smaller, indicating that higher $\mathrm{T}_{\mathrm{c}}$ decreases the crystalliza-

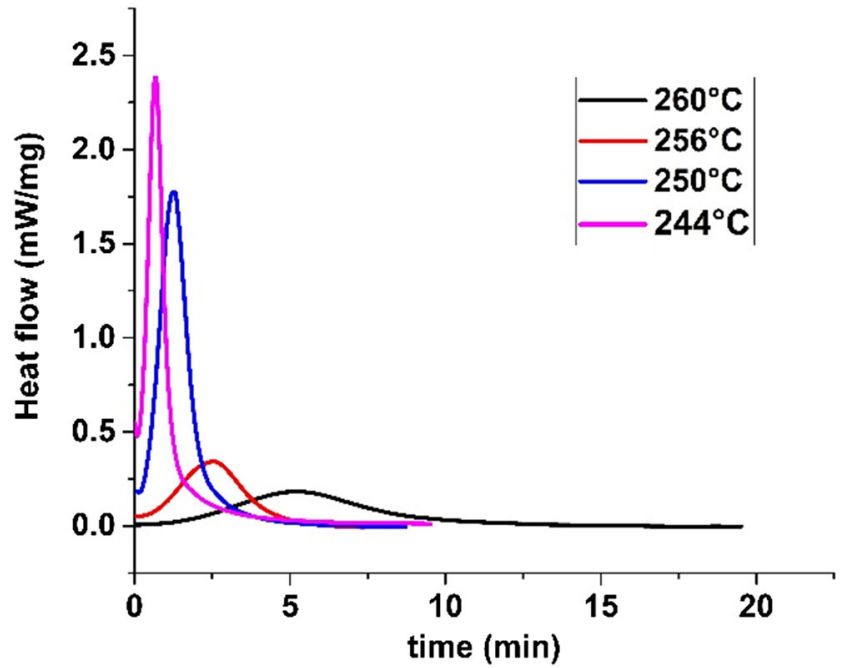

Fig. 1 The heat flow curves of PPS composites at different isothermal temperatures from melt point

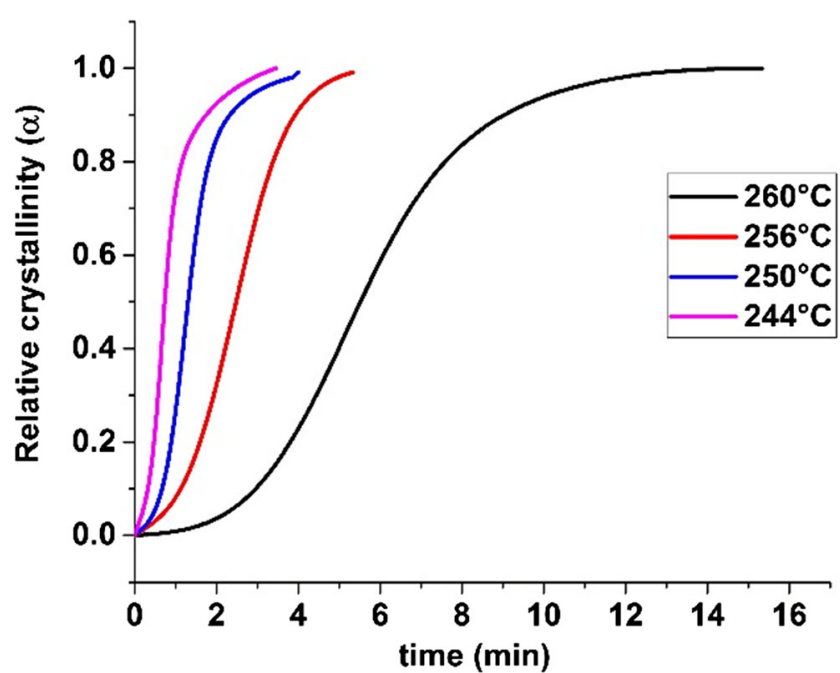

Fig. 2 The relative crystallinity curves of PPS composites at various isothermal temperatures 


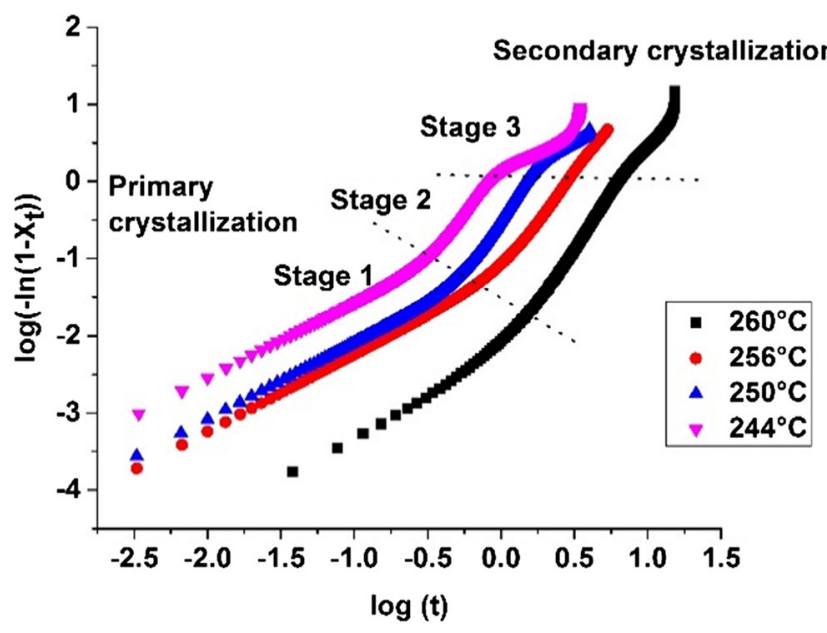

Fig. 3 Avrami Plot of $\log (-\ln (1-\chi(t)))$ against $\log t$ for isothermal crystallization of PPS composites

tion rate. In stage 2 , the $\mathrm{k}_{\mathrm{c}}$ increase to a relative higher value above 2 , this means that in this stage, the crystallization rate is faster than that in the first stage. In contrast, secondary crystallization seems to be non-linear and it seems hardly to be explained by the Avrami model.

In addition, we may define a crystallization half-time, $\mathrm{t}_{1 / 2}$, as the time required for $\chi(t)$ to achieve one half of $\chi(\infty)$; i.e.,

$\frac{\chi_{t_{1 / 2}}}{\chi_{\infty}}=1 / 2$

Plotting of $\log \left(t_{1 / 2}\right)$ against $T_{c}$ can be seen in Fig. 4. One can see that with increasing $T_{c}, t_{1 / 2}$ has an straightly increasing trend.

\section{Non-isothermal crystallization behavior}

DSC curves obtained at different cooling rates ranging from 5 to $25{ }^{\circ} \mathrm{C}$ for PPS are shown in Fig. 5. One can note that the cooling rate has a significant effect on the crystallization behavior of PPS and the crystallization peak temperature corresponding to the maximum crystallization shifts to lower temperature with the cooling rate increasing. For PPS crystallization, it is interesting to note the exothermic crystallization peaks are single and very sharp. This implies secondary

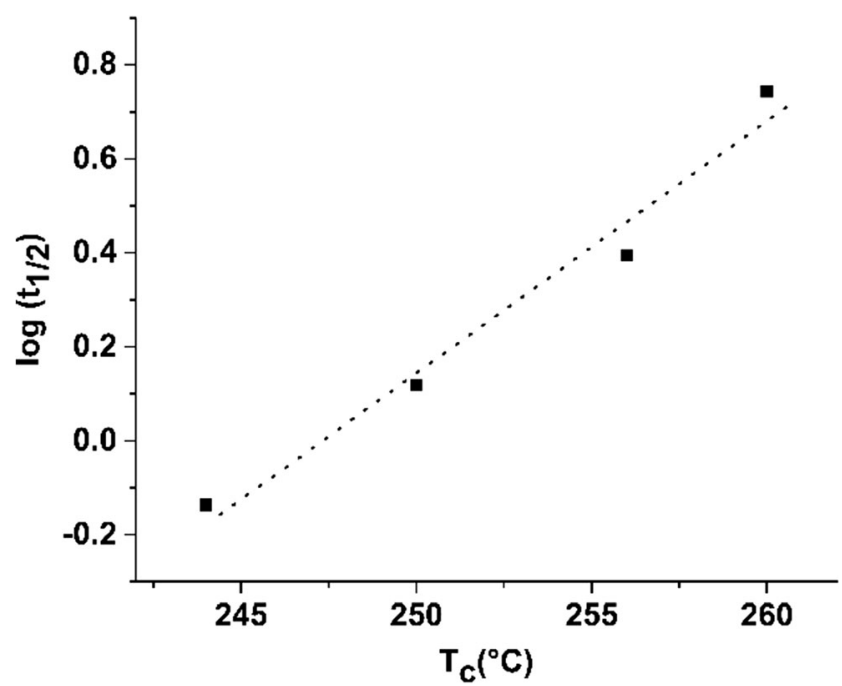

Fig. 4 Plot of $\log \left(t_{1 / 2}\right)$ against $T_{c}$

crystallization has no obvious effect on the PPS nonisothermal crystallization behavior.

Figure 6 shows the results of relative crystallization $\alpha$ as a function of crystallization time at different cooling rates. One can note all curves show S-sharp and the relative crystallization increases very slowly initially and afterwards, that the slope of curve enhances sharply in the middle period, and then tends to be slow in the end. Also, it can be seen the crystallization time is mainly dependent on cooling rate since the crystallization time duration reduces rapidly with the cooling rate rising.

Also, it should be noticed that the $t_{1 / 2}$ decrease with increasing cooling rates (see Fig. 7). This mainly because the higher cooling rate has a higher crystallization rate, which will definitely shorten the accomplishment time of crystallization.

\section{Jeziorny model}

Based on Avrami model, Jeziorny model [35] is commonly used to characterize the non-isothermal crystallization process, and the equation can be written as follows [36-39]:

$$
\begin{aligned}
& \alpha=\ln [-\ln (1-\chi(\mathrm{t}))]=\ln K+n \ln t \\
& \ln K_{C}=\frac{\ln K}{\beta}
\end{aligned}
$$

Table 1. Isothermal crystallization kinetic parameters calculated from the Avrami

\begin{tabular}{|c|c|c|c|c|c|c|c|}
\hline \multirow{3}{*}{$\begin{array}{l}\text { Samples } \\
\text { PPS/GF }\end{array}$} & \multirow[t]{3}{*}{ Isothermal temperatures $\left({ }^{\circ} \mathrm{C}\right)$} & \multicolumn{6}{|c|}{ Primary crystallization } \\
\hline & & \multicolumn{3}{|c|}{ Stage one } & \multicolumn{3}{|c|}{ Stage two } \\
\hline & & $\mathrm{k}_{\mathrm{c}}$ & $\mathrm{n}$ & $\mathrm{R}^{2}$ & $\mathrm{k}_{\mathrm{c}}$ & $\mathrm{n}$ & $\mathrm{R}^{2}$ \\
\hline & 244 & 0.247 & 0.969 & 0.999 & 2.436 & 1.413 & 0.998 \\
\hline & 250 & 0.082 & 0.996 & 1 & 2.902 & 0.317 & 0.997 \\
\hline & 256 & 0.057 & 0.996 & 0.999 & 2.511 & 0.069 & 0.999 \\
\hline & 260 & 0.0083 & 1.3 & 0.987 & 2.314 & 0.008 & 0.996 \\
\hline
\end{tabular}
equation. 


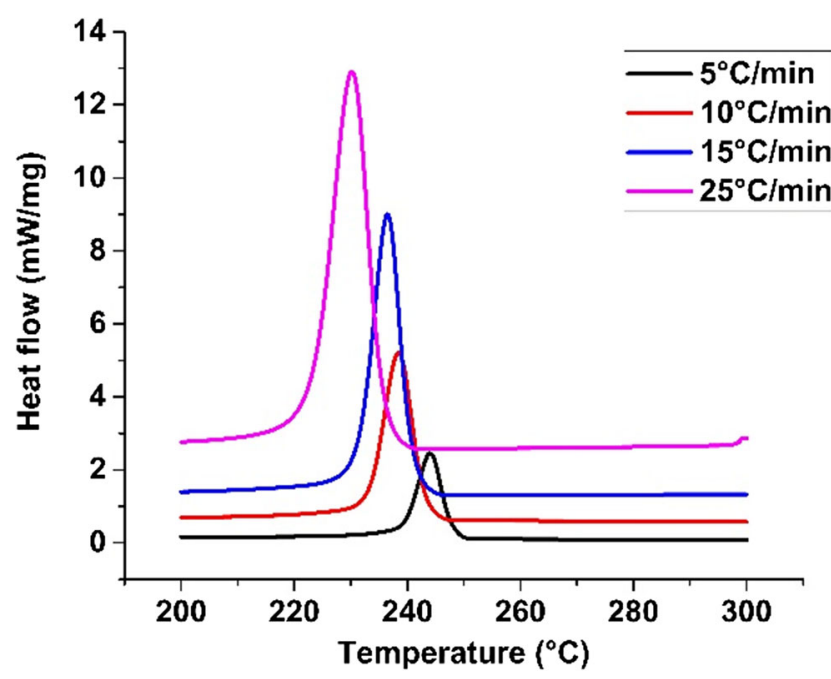

Fig. 5 The heat flow curves of PPS composites at various cooling rates $\left(5 \sim 25{ }^{\circ} \mathrm{C} / \mathrm{min}\right)$

Where $\alpha$ is the fraction of relative crystallinity and $\chi(\mathrm{t})$ is relative crystallization fraction at time $(\mathrm{t}) ; K$ is crystallization rate constant; $\mathrm{n}$ is the Avrami constant and $K_{\mathrm{c}}$ is corrected crystallization rate constant, $\beta$ is cooling rate.

After plotting the curve according to this model, one can note the plot of $\ln (-\ln (1-\chi(\mathrm{t})))$ against $\ln \mathrm{t}$ gives a straight line with a high $\mathrm{R}^{2}(>0.99)$ for all cooling rates(see Fig. 8). This means Jeziorny model can describe and verify the non-isothermal crystallization process for this PPS/GF material very well. Also, it is interesting to note from Table 2 the parameter $K_{\mathrm{c}}$ is related to the rate of crystallization. The value of $K_{\mathrm{c}}$ increases with the cooling rate rising, presenting that the crystallization rate becomes faster. This means that increasing cooling rate can improve the crystallization rate of PPS/GF under study.

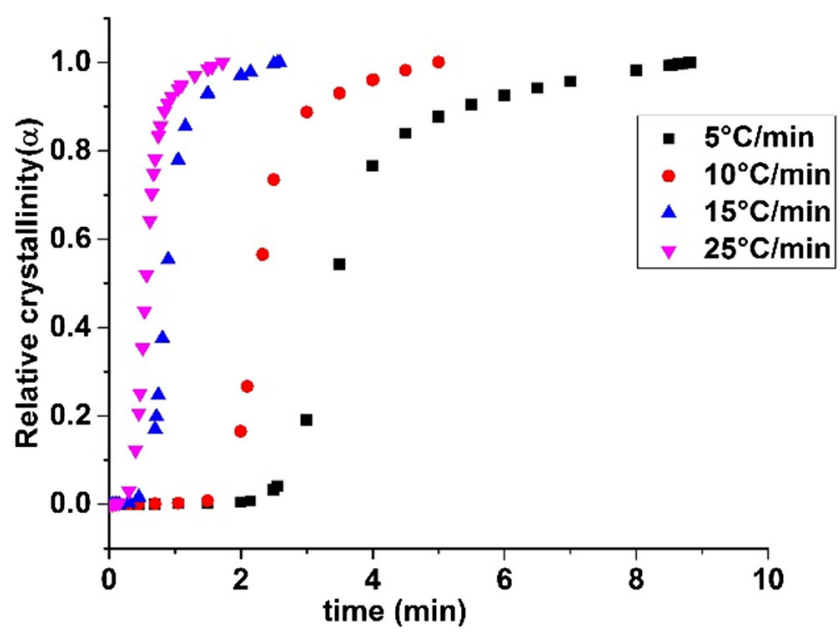

Fig. 6 The relative crystallinity curves of PPS composites at various cooling rates $\left(5 \sim 25^{\circ} \mathrm{C} / \mathrm{min}\right)$

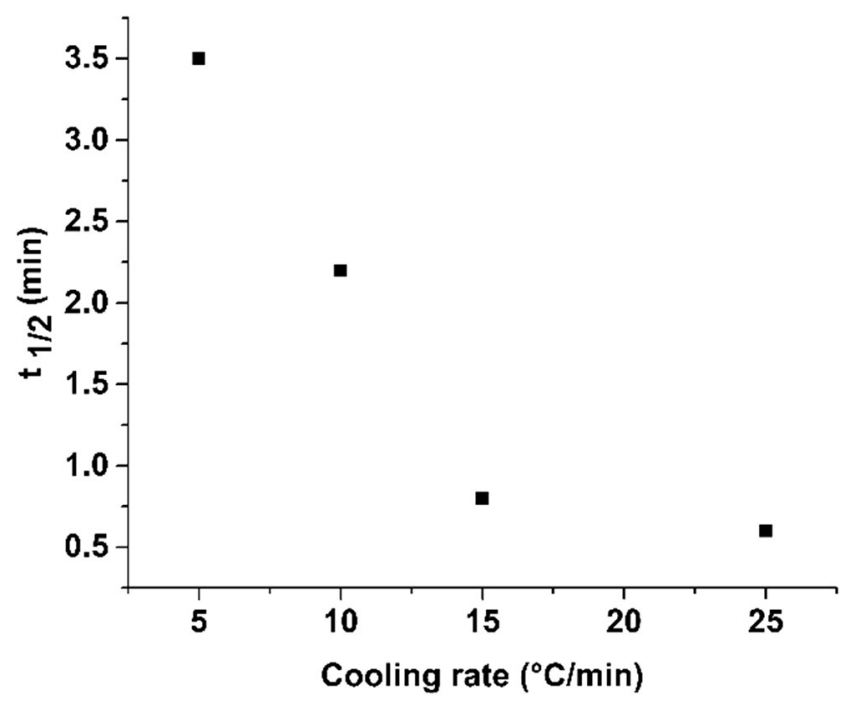

Fig. 7 The relationship of crystallization half time $t_{1 / 2}$ and cooling rate

\section{Mo model}

Mo model was proposed by a combination of Ozawa equation and Avrami equation to describe the non-isothermal crystallization kinetics of polymers, which can refer to the following equation $[40,41]$ :

$\ln k+n \ln t=\ln K(T)-m \ln \beta$

$\ln \beta=\ln F(T)-\alpha \ln t$

Where $\alpha=n / m, F(T)=[K(T) / k]^{1 / m} . F(T)$ is related to the cooling rate, it represents the speed of the crystallization and $\mathrm{m}$ is the Ozawa exponent. With this relationship, one can plot the curve $\ln \beta$ against $\ln t$ (see Fig. 9).

More parameters can be seen in Table 3 , high $\mathrm{R}^{2}(>0.94)$ indicates that Mo model can well describe the crystallization behavior of PPS/GF composite materials.

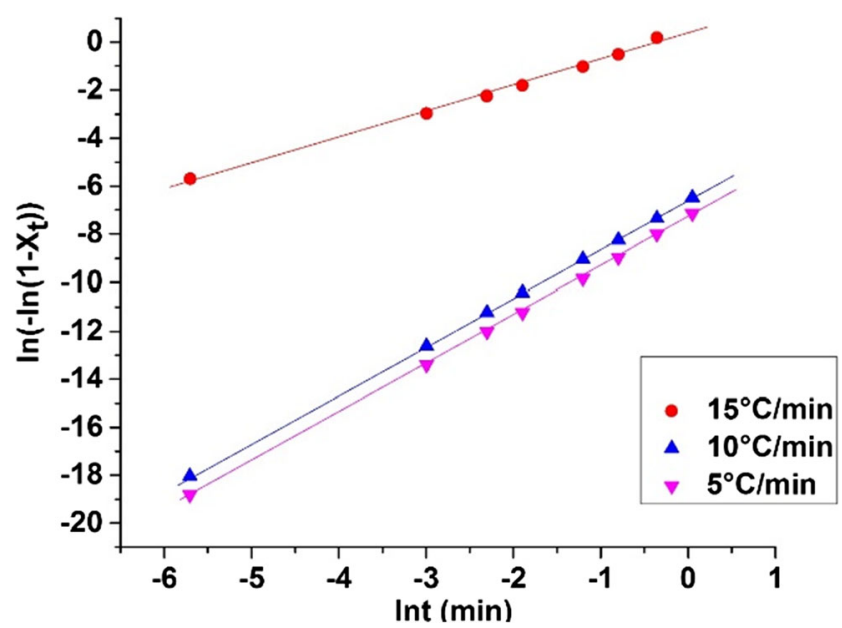

Fig. 8 Plot of $\ln (-\ln (1-\chi(\mathrm{t})))$ against $\ln \mathrm{t}$ at various cooling rates $\left(5 \sim 15{ }^{\circ} \mathrm{C} / \mathrm{min}\right)$ 
Table 2. Non-isothermal crystallization kinetics parameters from Jeziorny model.

\begin{tabular}{lllll}
\hline & $\mathrm{R}^{2}$ & $\mathrm{n}$ & $\mathrm{Ln} \mathrm{K}$ & $\mathrm{K}_{\mathrm{c}}$ \\
\hline $5{ }^{\circ} \mathrm{C} / \mathrm{min}$ & 0.99 & 2.02 & -7.33 & 0.23 \\
$10^{\circ} \mathrm{C} / \mathrm{min}$ & 1 & 2.00 & -6.61 & 0.52 \\
$15^{\circ} \mathrm{C} / \mathrm{min}$ & 0.99 & 1.08 & 0.34 & 1.02 \\
$25^{\circ} \mathrm{C} / \mathrm{min}$ & 0.99 & 3.55 & 0.91 & 1.04 \\
\hline
\end{tabular}

\section{Activation energy of non-isothermal crystallization}

To calculate the activation energy in non-isothermal crystallization, Kissinger and coworkers [42] proposed a useful equation based on $\mathrm{n}$-order kinetic model as follows:

$\ln \frac{\beta}{T_{p}^{2}}=\ln \frac{A R}{E}-\ln [G(\alpha)]-\frac{E}{R T_{p}}$

Where $\beta$ is the cooling rate, $T_{p}$ is the crystallization peak temperature. $\mathrm{A}$ is the pre-exponential factor and $\mathrm{R}$ is the universal gas constant. E is the activation energy and $G(\alpha)$ is the conversion function. With this Kissinger equation, a good linear relationship is traced between $\ln \frac{\beta}{T_{p}^{2}}$ vs. $\frac{1}{T p}$ (see

Fig. 10), and the activation energy in non-isothermal crystallization is obtained $(-58.78 \mathrm{~kJ} / \mathrm{mol})$.

\section{Further discussion}

\section{Evolution of crystallization behavior during thermal aging}

In general, thermal aging process leads to a phenomenon involving a slow and irreversible change in terms of materials'

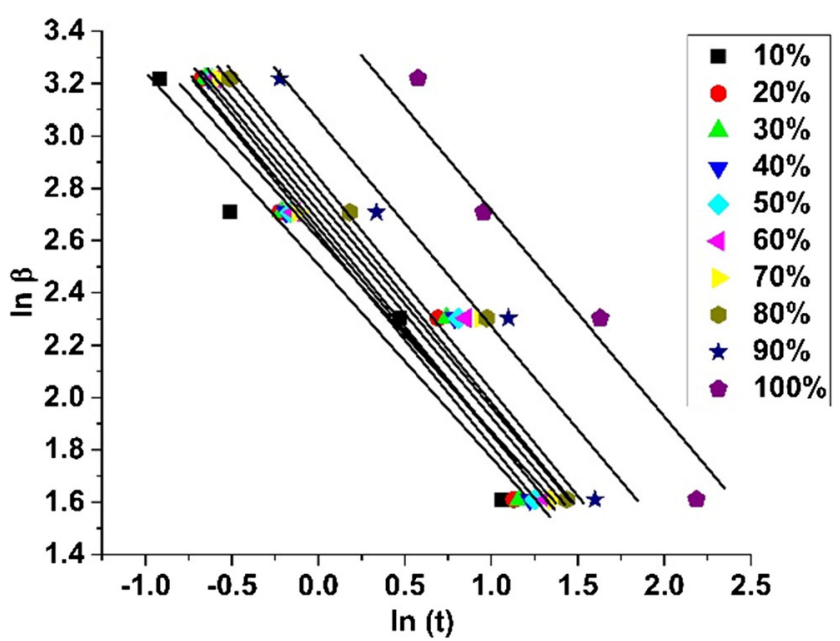

Fig. $9 \ln \beta$ versus $\ln t$ for non-isothermal crystallization at different relative crystallinities
Table 3. Non-isothermal crystallization kinetics parameters from Mo model.

\begin{tabular}{llllllll}
\hline & $\mathrm{R}^{2}$ & Ln F(T) & $\mathrm{a}$ & & $\mathrm{R}^{2}$ & $\mathrm{Ln} F(\mathrm{~T})$ & $\mathrm{a}$ \\
\hline $10 \%$ & 0.96 & 0.73 & 2.48 & $60 \%$ & 0.95 & 0.49 & 3.30 \\
$20 \%$ & 0.95 & 0.56 & 3.35 & $70 \%$ & 0.94 & 0.45 & 3.30 \\
$30 \%$ & 0.95 & 0.53 & 3.35 & $80 \%$ & 0.97 & 0.43 & 3.36 \\
$40 \%$ & 0.95 & 0.50 & 3.33 & $90 \%$ & 0.96 & 0.42 & 3.37 \\
$50 \%$ & 0.95 & 0.49 & 3.33 & $10 \%$ & 0.95 & 0.36 & 3.41 \\
\hline
\end{tabular}

properties. XRD is a powerful technique to analyze the crystallinity of materials. One can see the result in Fig. 11, the virgin sample has some obvious peaks at about $2 \theta=20.3^{\circ}$, which corresponds to the crystallized part in PPS/GF polymer composite. Interestingly, when the samples were treated in oven at different temperatures $\left(100{ }^{\circ} \mathrm{C}\right.$ to $\left.200{ }^{\circ} \mathrm{C}\right)$ for $24 \mathrm{~h}$, the peaks tend to increase and this implies some thermal treatment can also increase the crystallinity of PPS/GF materials.

The following part can be found in the thesis of Zuo [43], but the authors of Zuo et al. have revised this relevant part for this paper.

It should also be noticed that the polymer does not oxidize or degrade in the same way at different physical states. In glassy state, the amorphous phase is relatively fixed and compact and the mobility of the chains is very low. Also, the reaction of the polymer with oxygen is more difficult and slower. Comparatively speaking, in rubbery state, the oxidation occurs more easily and quickly. In the case of PPS composite materials, the result of the DMA test (Fig. 12) indicates that during oxidation at $140{ }^{\circ} \mathrm{C}, 160^{\circ} \mathrm{C}, 180{ }^{\circ} \mathrm{C}$ and $200{ }^{\circ} \mathrm{C}$, the amorphous phase is rubbery state. At $100^{\circ} \mathrm{C}$, this phase stays in the glass transition zone corresponding to a lower molecular mobility and reactivity. So, one should note in

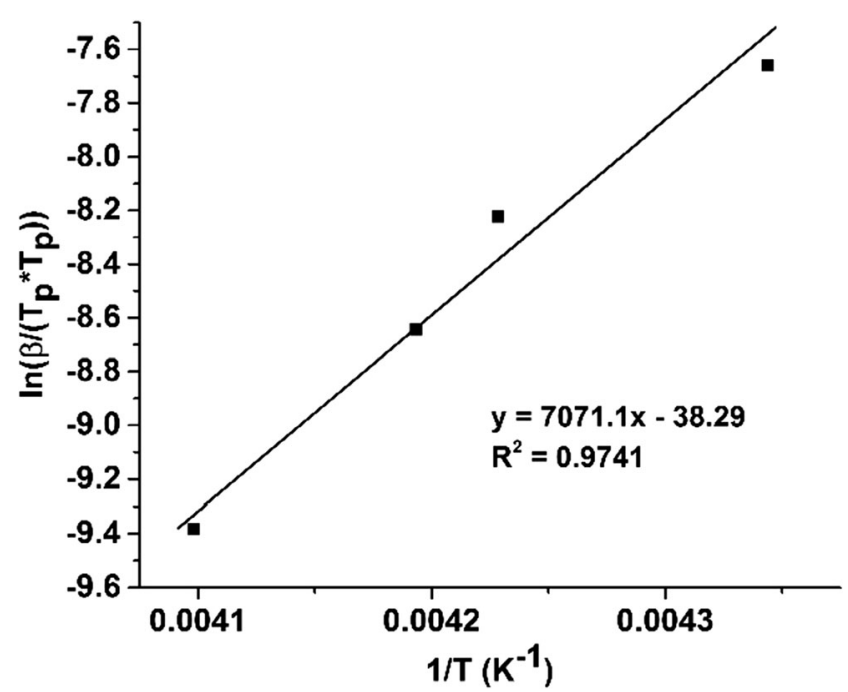

Fig. 10 Kissinger plot for calculating the non-isothermal crystallization activation energy of PPS/GF composite materials 


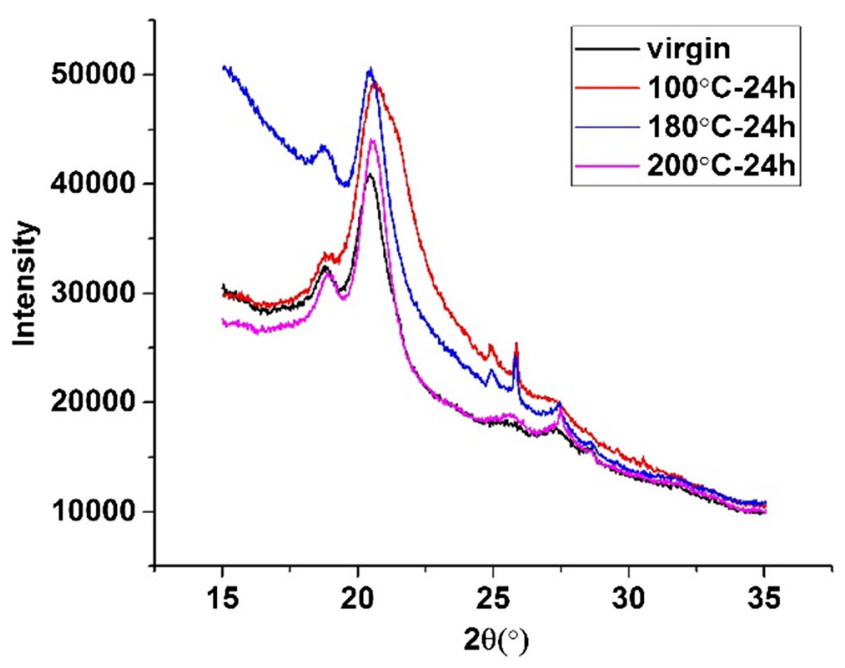

Fig. 11 XRD result obtained from PPS/GF sample

mind, the physical state is also related to the crystallization behaviors of polymer materials. Regarding the study of physical state, there is another further publication in our ongoing systematic research.

PPS is a semi-crystalline polymer, with an amorphous phase and a crystalline phase. The amorphous phase is much less compact. The oxygen can easily attack sites, which are the amorphous phase while oxygen cannot diffuse in the crystalline phase. Consequently, the thermal aging of the PPS has eventually resulted into the chemical structure change of the amorphous phase. This modification can be displayed in different ways: the crosslinking (appearing in certain cases and for certain period of aging), the scission of the macromolecular chains, the reduction of the molar mass, the embrittlement, the stiffening, the reorientation of the macromolecules, ... All these phenomena will happen in the amorphous phase and the crystalline phase during this period remains relatively intact. To understand the influence of thermal aging on the

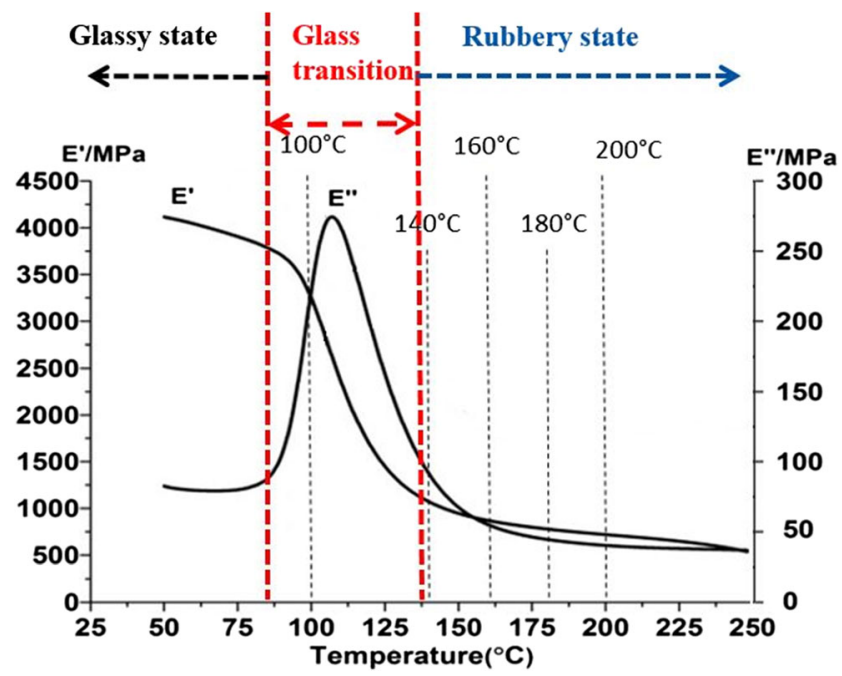

Fig. 12 Typical DMA results: different physical states (glassy and rubbery) and corresponding thermal aging temperature zones mechanical properties, it is necessary to study this morphological evolution. The change in mechanical properties is more comprehensive through this microstructural modification. In the case of PPS/GF composite, the morphological characteristics can be tracked from the results of DSC and DMA tests based on virgin and aged PPS/GF samples (at $200{ }^{\circ} \mathrm{C}$ ). Then it can be confirmed the $\mathrm{T}_{\mathrm{g}}$, the $\mathrm{T}_{\mathrm{f}}$, the crystallinity degree and the constants of the kinetic model of crystallization. Table 4 summarizes all these results.

One can notice that the $\mathrm{T}_{\mathrm{g}}$ increases from $106{ }^{\circ} \mathrm{C}$ (virgin sample) to $121^{\circ} \mathrm{C}$ (after $1080 \mathrm{~h}$ aging at $200{ }^{\circ} \mathrm{C}$ ). This improvement can be explained as follows: (short-term) crosslinking and the reorientation and stiffening of macromolecules are derived from the chains breaking through oxidation and macromolecules tend to be less mobile in the amorphous zone.

It is also observed that the degree of crystallinity improves from $44 \%$ (virgin sample) to $56 \%$ after $96 \mathrm{~h}$ of aging at $200{ }^{\circ} \mathrm{C}$. After a long period of oxidation $\left(1080 \mathrm{~h}\right.$ at $\left.200{ }^{\circ} \mathrm{C}\right)$, the degree of crystallinity falls to $36.6 \%$. It is very hard to explain this consequent drop in the crystallinity rate. Comparatively speaking, at this stage of degradation $(1080 \mathrm{~h})$ at $200^{\circ} \mathrm{C}$, the amorphous phase is seriously damaged and the morphological texture is totally modified.

In regard to the modification of the crystalline phase during thermal aging, the analysis of the change of the values concerning the constants of the model enables us to obtain the following findings:

- The constant $\mathrm{n}$ depends on the nature of nucleation, the geometry of the crystallites and the density of the spherulites. The value of $n$ is about 2 for virgin samples and aged at $200{ }^{\circ} \mathrm{C}$ up to $144 \mathrm{~h}$. It can be assumed that during this period the crystalline phase is not very modified while, $\mathrm{n}$ decreases to 0.8 for the samples aged after $1080 \mathrm{~h}$ at $200^{\circ} \mathrm{C}$. This may indicate that the PPS material has almost lost its ability to nucleate and crystallize due to well excessive thermal aging when compared to its initial state.

Table 4. The parameters obtained from DMA and DSC.

\begin{tabular}{ccccc}
\hline & Amorphous phase & \multicolumn{2}{l}{ Crystalline Phase } \\
\cline { 3 - 5 } Samples & $\mathrm{T}_{\mathrm{g}}{ }^{(*)}\left({ }^{\circ} \mathrm{C}\right)$ & $\mathrm{X}_{\mathrm{c}}{ }^{(* *)}$ & $\mathrm{n}^{(* *)}$ & $\mathrm{K}_{\mathrm{c}}{ }^{(* *)}$ \\
\hline Virgin & 106 & 44.2 & 2.00 & 0.5 \\
$200{ }^{\circ} \mathrm{C}-20 \mathrm{~h}$ & 108 & 45.0 & 2.10 & 0.88 \\
$200{ }^{\circ} \mathrm{C}-96 \mathrm{~h}$ & 108 & 55.8 & 2.19 & 0.82 \\
$200{ }^{\circ} \mathrm{C}-144 \mathrm{~h}$ & - & 52.9 & 2.27 & 0.97 \\
$200{ }^{\circ} \mathrm{C}-1080 \mathrm{~h}$ & 121 & 36.6 & 0.8 & 0.6 \\
\hline
\end{tabular}

${ }^{(*)} \mathrm{T}_{\mathrm{g}}$, obtained by DMA test at the peak of $\mathrm{E} ",(\mathrm{f}=1 \mathrm{~Hz}) ;{ }^{(* *)} \mathrm{X}_{\mathrm{c}}, \mathrm{n}, \mathrm{K}_{\mathrm{c}}$, obtained by DSC with a cooling speeding of $10{ }^{\circ} \mathrm{C} / \mathrm{min}$ 
Fig. 13 Storage modulus (a), loss modulus (b), $\tan \delta$ (c) evolution as a function of aging time at $200{ }^{\circ} \mathrm{C}$ $(10 \mathrm{~Hz})$
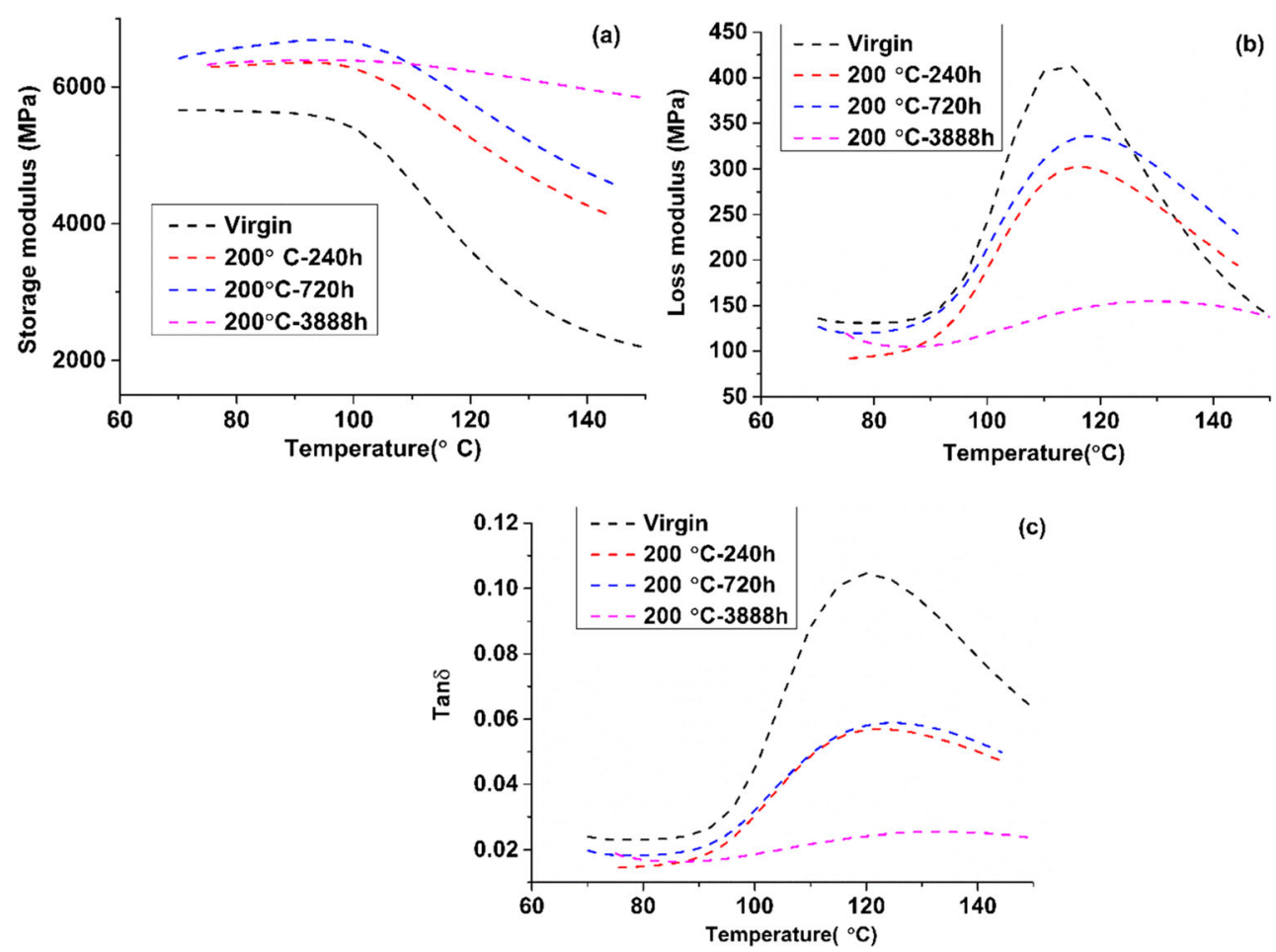

(c)

Moreover, it is well known that the $\tan \delta$ is extremely sensitive to all kinds of transitions, relaxation processes, structural heterogeneities, and morphologies of multiphase systems (such as polymers, polymer blends, fillers or composite materials) $[44,45]$. Figure $13(\mathrm{c})$ shows the $\tan \delta$ evolution as a function of aging time at $200{ }^{\circ} \mathrm{C}$. One can observe that with the aging time increasing, the $\tan \delta$ exhibit the decreasing trend. Fuente et al. [45] concluded in their research that the damping parameter $(\tan \delta)$ was a sensitive indicator of degradation. Therefore, at temperature well above $\mathrm{Tg}$, the modulus tends to increase whereas the damping decreases with a rise degree of degradation. In our results, it is confirmed for all of samples, the $\tan \delta$ declines with the aging time increasing. This indicates the degree of degradation seems more and more serious with the aging time increasing at $200{ }^{\circ} \mathrm{C}$. Also, it is of importance to note that the evolution of $\tan \delta$ in a study of aged PPS samples may be a valuable tool for predicting the service life of these materials. Also, it is significant to notice that the results are consistent with the previous study in reference of Fuente et al. [45], which also proves in further that the damping parameter $(\tan \delta)$ can be as an indicator or parameter to reflect obviously the degree of degradation in materials.

\section{Conclusions}

In this paper, isothermal and non-isothermal crystallization behaviors of PPS/GF were systematically studied and a wide range of commonly used models were applied in this material. 
Also, this paper emphasizes the thermal aging effect on crystallization behaviors and dynamic mechanical properties. The main conclusions are presented as follows:

- To PPS/GF (30\% wt, glass fibers) composite, the isothermal crystallization behaviors seem hardly to be described while the non-isothermal crystallization can be well described by a wide ranges of classic crystallization kinetic models.

- The crystallization behaviors of PPS materials can be significantly affected by the thermal aging, with an evolution of degree of crystallinity increasing from $44 \%$ (virgin sample) to $56 \%$ after $96 \mathrm{~h}$ of aging at $200{ }^{\circ} \mathrm{C}$. After a long period of oxidation up to $1080 \mathrm{~h}$ at $200{ }^{\circ} \mathrm{C}$, the crystallinity degree decreases to $36.6 \%$.

- In the long term (such as $200{ }^{\circ} \mathrm{C}-1080 \mathrm{~h}$ ), the value of $\mathrm{K}_{\mathrm{c}}$ (0.6) shows that the polymer crystallizes more slowly during crystallization when aging is dramatically excessive and the polymer is completely degraded.

- DMA results imply that thermal aging may lead to more crosslinking reaction and restriction of molecule mobility. Also, the degree of degradation seems more and more serious with the aging time increasing at $200{ }^{\circ} \mathrm{C}$.

Acknowledgements The authors are grateful to Dr. R.C. Benevides and Dr. Manuel Henner (Valeo) for collaboration and fruitful discussions. Valeo Company is also gratefully acknowledged for providing the material. Financial support from the CASCADE program under project "FSN Calcul Intensif et Simulation Numérique" by DGE is gratefully acknowledged.

The authors also thank China Scholarship Council (CSC) for their funding of Peiyuan Zuo's thesis.

\section{References}

1. Park M, Park JH, Yang BJ, Cho J, Kim SY, Jung I (2018) Enhanced interfacial, electrical, and flexural properties of polyphenylene sulfide composites filled with carbon fibers modified by electrophoretic surface deposition of multi-walled carbon nanotubes. Compos A: Appl Sci Manuf 109:124-130

2. Zhao L, Yu Y, Huang H, Yin X, Peng J, Sun J, Huang L, Tang Y, Wang L (2019) High-performance polyphenylene sulfide composites with ultra-high content of glass fiber fabrics. Compos Part B 174:106790

3. Backe D, Balle F (2016) Ultrasonic fatigue and microstructural characterization of carbon fiber fabric reinforced polyphenylene sulfide in the very high cycle fatigue regime. Compos Sci Technol 126:115-121

4. Stoeffler K, Andjelic S, Legros N, Roberge J, Schougaard SB (2013) Polyphenylene sulfide (PPS) composites reinforced with recycled carbon fiber. Compos Sci Technol 84:65-71

5. Maaroufi MA, Carpier Y, Vieille B, Gilles L, Coppalle A, Barbe F (2017) Post-fire compressive behaviour of carbon fibers woven-ply Polyphenylene sulfide laminates for aeronautical applications. Compos Part B 119:101-113

6. Liu D, Zhu Y, Ding J, Lin X, Fan X (2015) Experimental investigation of carbon fiber reinforced poly (phenylene sulfide) composites prepared using a double-belt press. Compos Part B 77:363-370
7. Zhu C, Zhang J, Xu J, Yin X, Wu J, Chen S, Zhu Z, Wang L, Wang H (2019) Aramid nanofibers/polyphenylene sulfide nonwoven composite separator fabricated through a facile papermaking method for lithium ion battery. J Membr Sci 588:117169

8. Luo D, Chen M, Xu J, Yin X, Wu J, Chen S, Wang L, Wang H (2018) Polyphenylene sulfide nonwoven-based composite separator with superior heat-resistance and flame retardancy for high power lithium ion battery. Compos Sci Technol 157:119-125

9. Huang H, Li Y, Zhao L, Yu Y, Xu J, Yin X, Chen S, Wu J, Yue H, Wang H (2019) A facile fabrication of chitosan modified PPS-based microfiber membrane for effective antibacterial activity and oil-inwater emulsion separation. Cellulose 26(4):2599-2611

10. Kim MH, Kim SH, Kim BS, Wee J-W, Choi B-H (2018) Characterization of injection-molded high-strength/high-stiffness thermoplastic hybrid materials containing thermotropic liquid crystal polymer (LCP), polyphenylene sulfide (PPS) with carbon fibers. Compos Sci Technol 168:272-278

11. Gopakumar TG, Ponrathnam S, Lele A, Rajan CR, Fradet A (1999) In situ compatibilisation of poly (phenylene sulphide)/wholly aromatic thermotropic liquid crystalline polymer blends by reactive extrusion: morphology, thermal and mechanical properties. Polymer 40(2):357-364

12. Xing J, Ni Q-Q, Deng B, Liu Q (2016) Morphology and properties of polyphenylene sulfide (PPS)/polyvinylidene fluoride (PVDF) polymer alloys by melt blending. Compos Sci Technol 134:184 190

13. Tóth LF, Sukumaran J, Szebényi G, De Baets P (2019) Tribomechanical interpretation for advanced thermoplastics and the effects of wear-induced crystallization. Wear 440-441:203083

14. Furushima Y, Nakada M, Yoshida Y, Okada K (2018) Crystallization/melting kinetics and morphological analysis of Polyphenylene sulfide. Macromol Chem Phys 219(2):1700481

15. Liu P, Dinwiddie RB, Keum JK, Vasudevan RK, Jesse S, Nguyen NA, Lindahl JM, Kunc V (2018) Rheology, crystal structure, and nanomechanical properties in large-scale additive manufacturing of polyphenylene sulfide/carbon fiber composites. Compos Sci Technol 168:263-271

16. Deng S, Cao L, Lin Z, Qiu W, Liang K, Li W (2014) Nanodiamond as an efficient nucleating agent for polyphenylene sulfide. Thermochim Acta 584:51-57

17. Chen JM, Woo E (1995) Sequential crystallization kinetics of poly (p-phenylene sulfide) doped with carbon or graphite particles. J Appl Polym Sci 57(7):877-886

18. Sheng-Ling J, Xiao-Yu G, Zhi-Yuan Z (2013) Nucleation effect of hydroxyl-purified multiwalled carbon nanotubes in poly ( $p$ phenylene sulfide) composites. J Appl Polym Sci 127(1):224-229

19. Lee KH, Park M, Kim YC, Choe CR (1993) Crystallization behavior of polyphenylene sulfide (PPS) and PPS/carbon fiber composites: effect of cure. Polym Bull 30(4):469-475

20. Lu SX, Cebe P (1996) Effects of annealing on relaxation behavior and charge trapping in film-processed poly (phenylene sulfide). J Appl Polym Sci 61(3):473-483

21. Lee S, Kim D-H, Park J-H, Park M, Joh H-I, Ku B-C (2013) Effect of curing poly (p-phenylene sulfide) on thermal properties and crystalline morphologies. Adv Chem Eng Sci 3:145-149

22. Boey F, Lee T, Khor K (1995) Polymer crystallinity and its effect on the non-linear bending creep rate for a polyphenylene sulphide thermoplastic composite. Polym Test 14(5):425-438

23. Chung J, Bodziuch J, Cebe P (1992) Effects of thermal history on crystal structure of poly (phenylene sulphide). J Mater Sci 27(20): 5609-5619

24. Caminiti R, D'llario L, Martinelli A, Piozzi A (2001) Poly (pphenylene sulfide) isothermal cold crystallization investigated by usual and unusual methods. Macromol Chem Phys 202(14):29022914 
25. Mai K, Mei Z, Xu J, Zeng H (1998) Effect of high-performance polymers on crystallization and multiple melting behavior of poly (phenylene sulfide). J Appl Polym Sci 69(4):637-644

26. Auer C, Kalinka G, Krause T, Hinrichsen G (1994) Crystallization kinetics of pure and Fiber-reinforced poly (Phenylene sulfide). J Appl Polym Sci 51(3):407-413

27. Desio GP, Rebenfeld L (1992) Crystallization of fiber-reinforced poly (phenylene sulfide) composites. I. Experimental studies of crystallization rates and morphology. J Appl Polym Sci 44(11): 1989-2001

28. Cole K, Noel D, Hechler J-J (1990) Crystallinity in PPS-carbon composites: a study using diffuse reflection FT-IR spectroscopy and differential scanning calorimetry. J Appl Polym Sci 39(9): 1887-1902

29. Yang J, Xu T, Lu A, Zhang Q, Tan H, Fu Q (2009) Preparation and properties of poly (p-phenylene sulfide)/multiwall carbon nanotube composites obtained by melt compounding. Compos Sci Technol 69(2):147-153

30. Wu D, Wu L, Wang J, Sun Y, Zhang M (2011) Effect of epoxy resin on the thermal behaviors and viscoelastic properties of poly (phenylene sulfide). Mater Chem Phys 128(1):274-282

31. Zuo P, Fitoussi J, Shirinbayan M, Bakir F, Tcharkhtchi A (2019) Thermal aging effects on overall mechanical behavior of short glass fiber-reinforced polyphenylene sulfide composites. Polym Eng Sci 59(4):765-772

32. Zuo P, Tcharkhtchi A, Shirinbayan M, Fitoussi J, Bakir F (2019) Overall investigation of poly (Phenylene sulfide) from synthesis and process to applications - a review. Macromol Mater Eng 304(5): 1800686

33. Zuo P, Tcharkhtchi A, Shirinbayan M, Fitoussi J, Bakir F (2019) Multiscale physicochemical characterization of a short glass fiberreinforced polyphenylene sulfide composite under aging and its thermo-oxidative mechanism. Polym Adv Technol 30(3):584-597

34. Avrami M (1940) Kinetics of phase change. II transformation-time relations for random distribution of nuclei. J Chem Phys 8(2):212224
35. Jeziorny A (1978) Parameters characterizing the kinetics of the nonisothermal crystallization of poly (ethylene terephthalate) determined by DSC. Polymer 19(10):1142-1144

36. Weng W, Chen G, Wu D (2003) Crystallization kinetics and melting behaviors of nylon $6 /$ foliated graphite nanocomposites. Polymer 44(26):8119-8132

37. Zhang Y, Jiang X, Guan Y, Zheng A (2005) Crystallization kinetics of ATPU grafted polypropylene. Mater Lett 59(28):3626-3634

38. Botines E, Puiggalí J (2006) Crystallization kinetics of poly (glycolic acid-alt-6-aminohexanoic acid). Eur Polym J 42(7): 1595-1608

39. Kuo M, Huang J, Chen M (2006) Non-isothermal crystallization kinetic behavior of alumina nanoparticle filled poly (ether ether ketone). Mater Chem Phys 99(2):258-268

40. Ozawa T (1971) Kinetics of non-isothermal crystallization. Polymer 12(3):150-158

41. Liu T, Mo Z, Wang S, Zhang H (1997) Nonisothermal melt and cold crystallization kinetics of poly (aryl ether ether ketone ketone). Polym Eng Sci 37(3):568-575

42. Kissinger HE (1957) Reaction kinetics in differential thermal analysis. Anal Chem 29(11):1702-1706

43. Zuo P (2018) Study of thermal aging effect on fatigue behaviors of a short glass fiber reinforced Polyphenylene sulfide (PPS/GF) composite, Doctor's thesis

44. Landel RF, Nielsen LE (1993) Mechanical properties of polymers and composites. CRC Press

45. Rodríguez O (2003) Dynamic mechanical study on the thermal aging of a hydroxyl-terminated polybutadiene-based energetic composite. J Appl Polym Sci 87(14):2397-2405 